\title{
ASPECTOS DA DIFERENÇA ONTOLÓGICA NA INTRODUÇÃO DE SER E TEMPO
}

\author{
Aspects of the ontological difference in the introduction of Being and Time
}

Fábio François M. da Fonseca*

\begin{abstract}
Resumo: Aprecio neste texto alguns desdobramentos da diferença ontológica que podem ser traçados a partir da discussão que abre Ser e Tempo a respeito dos preconceitos que obstruíram a questão de ser ao longo da tradição metafísica. Tentarei argumentar que Heidegger consegue extrair destes preconceitos três aporias que provam indiretamente uma implicação específica da diferença ontológica que tem consequências metodológicas para a ontologia fundamental, a conclusão de que o ser não é um ente subsistente a ser determinado segundo sentenças assertóricas. Finalmente, tentarei explicar por que Heidegger contorna logo de início o encaminhamento da ontologia tradicional que presume que o ser é primordialmente o ser de um ente subsistente.

Palavras-chave: Diferença ontológica. Metafísica. Questão do Ser.
\end{abstract}

\begin{abstract}
I analyze in this paper some consequences of the ontological difference that can be drawn from the discussion that opens Being and Time about the prejudices that blocked the question of being throughout the metaphysical tradition. I try to argue that Heidegger manages to extract from these prejudices three aporias that indirectly prove a specific implication of the ontological difference that has methodological consequences for fundamental ontology, namely, the conclusion that being is not an extant entity that could be determined by categorical judgments. Finally, I try to explain why Heidegger bypasses from the outset the traditional ontology's approach that assumes that being is primarily being of an extant entity. Keywords: Ontological difference. Metaphysical. Question of Being.
\end{abstract}

\footnotetext{
* Doutorando pelo Programa de Pós-graduação em Lógica e Metafísica da Universidade Federal do Rio de Janeiro (UFRJ). Contato: fitak7@gmail.com
}

\begin{tabular}{|c|c|c|c|c|c|}
\hline intuitio & $\begin{array}{c}\text { ISSN } \\
1983-4012\end{array}$ & Porto Alegre & Vol.7 $-\mathrm{N}^{\mathrm{o}} .1$ & $\begin{array}{c}\text { Junho } \\
2014\end{array}$ & p.32-42 \\
\hline
\end{tabular}




\section{Dois níveis da diferença ontológica}

A tese de que o ser não é um ente é recorrente e fundamental em todo pensamento de Heidegger, mas não surge sempre com o mesmo caráter e sob a mesma justificativa. Em geral, é conduzida como um postulado metodológico, que permitiria manter o questionamento ontológico focado no seu tema, sem dispersar-se em ontologias regionais acerca de um tipo ou outro de ente ${ }^{1}$. Há pelo menos dois caminhos que seriam já descartados, uma vez adotada esta tese, e que compartilham a mesma expectativa de que a investigação ontológica pode ser conduzida segundo proposições assertóricas: [i] tomar o ser como uma propriedade entre outras do ente; [ii] tomar o ser como um outro ente tido por causa de todos os outros. No entanto, nunca é de todo claro por que a tese deve ser adotada e todas estas hipóteses, que foram exploradas com desenvoltura ao longo da tradição filosófica, deveriam ser descartadas de antemão.

É tentador propor que a diferença ontológica apenas articula a compreensão de ser em que nos orientamos previamente e que posiciona possibilidade e efetividade do ente como polos contrapostos. Porém se a tendência a tomar o ser por ente não for categoricamente afastada, não se pode contornar tão facilmente o movimento que reduz possibilidades a contingências reais, ou que só tem por consequentes possibilidades que admitam tal redução. Também tem sido com frequência alegado que a diferença ontológica não é estabelecida e traçada por uma diligência de nossa parte, mas que ela nos antecede enquanto algo em que somos previamente situados e a partir da qual sustentamos qualquer compreensão de $\operatorname{ser}^{2}$. Isto sugere que só muito tardiamente ela é um postulado metodológico e que primordialmente trata-se do próprio advento do ente sob o pano de fundo do ser e seu simultâneo retraimento, o que explicaria a tendência a tomá-lo por ente. De qualquer forma, tal evento não depende primordialmente de uma decisão do filósofo. De fato, Heidegger antecipa esta sugestão ao conceder que a distinção não pode ser elucidada sem tomar-se em conta o que ele entende por temporalidade ${ }^{3}$.

Invocando a temporalidade, Heidegger mostra que na questão da diferença ontológica pretende pensar ao mesmo tempo as questões do método da ontologia e do caráter histórico do ser, o que poderia então ser explicado ao se propor que o método de explicitação resgata o evento de instauração pré-ontológica e este, por sua vez, dá a possibilidade do método. Infelizmente, a noção de temporalidade de Heidegger é muito peculiar e bastante complexa, e só com muito esforço de compreensão ela serve às suas pretensões de superação do tradicional dilema entre determinismo e voluntarismo. De qualquer forma, se uma elucidação plena da diferença ontológica é impossível numa

\footnotetext{
${ }^{1}$ Heidegger, M.. Os Problemas Fundamentais da Fenomenologia. Tradução Marco Antônio Casanova. $2^{\mathrm{a}}$ ed.. Petrópolis: Vozes, p. 31 (GA 24, p. 22-23).

${ }^{2}$ Gadamer, H.-G.. Hermenêutica em Retrospectiva - Volume I. $2^{\mathrm{a}}$ ed. Tradução Marco Antônio Casanova. Petrópolis: Vozes, 2007, p. 92.

${ }^{3}$ Heidegger, M.. Os Problemas Fundamentais da Fenomenologia. Tradução Marco Antônio Casanova. $2^{\mathrm{a}}$ ed.. Petrópolis: Vozes, 2012, p. 31 (GA 24, p. 23).
}

\begin{tabular}{|c|c|l|l|l|l|}
\hline intuitio & $\begin{array}{c}\text { ISSN } \\
1983-4012\end{array}$ & Porto Alegre & Vol.7 $-\mathrm{N}^{\circ} .1$ & $\begin{array}{c}\text { Junho } \\
2014\end{array}$ & p.32-42 \\
\hline
\end{tabular}


consideração preliminar, é importante ao menos esclarecer que aspecto ou implicação desta tese pode ser estabelecido, e se tal implicação vai de algum modo justificar a escolha de um tipo de abordagem em detrimento de outra para o tema da ontologia.

Quando a diferença ontológica é enunciada, não se considera em geral o que se quer dizer por “ente”, em especial não se leva em conta que Heidegger é um dos poucos filósofos a propor que além de objetos há entes que não são determináveis mediante enunciados predicativos, quer dizer, que não são entes subsistentes no sentido de Vorhanden. Isto é certo, por que embora ser e ser-aí guardem uma reciprocidade não de todo clara, eles não são idênticos. Mas por outro lado, neste ponto inicial da investigação, Heidegger está discutindo ainda com uma tradição que ignora esta sutileza e que não só entende que o ser é um ente mas também que o ente é sempre um ente subsistente, no sentido de ser determinado mediante sentenças que atribuem predicados. Mesmo o sujeito, que orienta as abordagens cartesianas e transcendentais, é um sujeito a que se atribui ideias, estados mentais, estados internos, representações etc.

Há portanto, um sentido lato da diferença ontológica, que deve manter contrapostos ser e qualquer ente, inclusive este ente que tem o modo peculiar de ser do ser-aí, o qual consiste em sustentar existencialmente uma compreensão de ser. Esta configuração mais abrangente da distinção é razoavelmente difícil de ser estabelecida, dada a reconhecida reciprocidade entre os eventos em que dá-se ser e em que o ser-aí [Dasein] existe $\left(\mathrm{SZ}^{4}, 212\right)$. Ela exige, pelo menos, o esclarecimento da temporalidade como horizonte da cura, de modo a que o ser-aí seja empenhado em possibilidades abertas no porvir, mas estas sejam a cada vez vinculadas e instanciadas num ter-sido que lhes solicita ou inspira, especificando e antecedendo seu âmbito de decisividade.

Mas há uma versão preliminar e específica da diferença ontológica que pode ser estabelecida em termos mais simples e justificada com argumentos mais acessíveis. Ser não é um ente e, em especial, não é um ente subsistente, o que implica que o sentido de ser não comporta um tratamento proposicional. Noutros termos, ao contrário das coisas, cuja quididade é apurada mediante asserções predicativas, ser não é um tema cuja elucidação possa ser conduzida sem problemas por este tipo de formulação discursiva. É esta diferença ontológica específica, que podemos chamar de real, que Heidegger procura estabelecer na introdução de Ser e Tempo. E ele pode fazê-lo sem recorrer a presunções ulteriores ainda por se apurar no curso da sua investigação, com base em uma série de dificuldades que resultam da forma lógica e do uso ordinário de enunciados predicativos uma vez que se pretenda empregá-los para explicitar o que entendemos por "ser".

\section{Três aporias da tradição}

Especificar a diferença ontológica nestes termos é importante para se justificar as opções

\footnotetext{
${ }^{4}$ Trechos de Ser e Tempo serão citados no corpo do texto, pela designação "SZ" e pela paginação da edição alemã.

\begin{tabular}{|c|c|l|l|l|l|}
\hline intuitio & $\begin{array}{c}\text { ISSN } \\
1983-4012\end{array}$ & Porto Alegre & Vol.7- $\mathrm{N}^{\circ} .1$ & $\begin{array}{c}\text { Junho } \\
2014\end{array}$ & p.32-42 \\
\hline
\end{tabular}
}


metodológicas de Ser e Tempo, em especial, a incursão numa analítica existencial, a abordagem hermenêutica e a suspensão da tendência a se tomar o tema como um ente subsistente a ser determinado por enunciados predicativos. Quando Heidegger discute os três preconceitos que recomendaram na tradição o esquecimento ou banalização da questão de ser, ele está também questionando sua premissa comum, a presunção de que esta questão foi satisfatoriamente exaurida a luz da aptidão ordinária para asserir enunciados. A tradição diz que o ser é a noção mais universal, que não comporta nem precisa de definição, uma vez que é compreensível por si mesma. Heidegger não só contesta estes preconceitos, mas os reverte para mostrar que a questão do ser resiste a ser articulada em termos proposicionais, uma vez que se considere três elementos formais desta competência discursiva: ser não é um gênero a figurar na posição de predicado, ser não é definível de modo a ocupar a posição de sujeito de atribuições, e ser não é acessível mediante uma evidência ordinária.

Ser não é um gênero (SZ, 3). Heidegger remete aqui a um argumento de autoridade razoavelmente convincente formulado por Aristóteles: "Não é possível que ser e um sejam gêneros; pois a diferença de qualquer gênero deve cada uma ser e ser uma, e é impossível para um gênero ser predicado de suas próprias diferenças." ${ }^{\circ}$. O trecho é denso e comporta interpretações sutilmente diversas. Adotarei a mais simples. O argumento é por redução ao absurdo. Todo o gênero tem uma diferença específica em relação a qual ele pode ser delimitado como o gênero que ele é, uma diferença pensada como fora dele portanto. Se o ser é um gênero, ele tem uma diferença específica que determina o não-ser. No entanto, a respeito desta diferença é preciso dizer que ela de algum modo é, assim como de suas instâncias. Contradição. Logo, temos motivos fortes para recusar que o ser seja um gênero ${ }^{6}$.

Esta formulação tem afinidades com a alegação de Kant de que a existência no sentido de atualidade ou efetividade não é um predicado real, e quem for simpático à sua refutação do argumento ontológico, não vai ter problemas em conceder este ponto ${ }^{7}$. Não por acaso, Heidegger explora e desenvolve esta formulação de Kant como uma versão da diferença ontológica ${ }^{8}$.

Ser não é definível $(\mathrm{SZ}, 4)$. Aqui Heidegger alega inicialmente a alardeada universalidade suprema da noção de "ser". Mas como esta pretensa universalidade não é de modo algum clara, cita um argumento de Pascal que é bem mais específico e econômico, por que se atém ao próprio procedimento proposicional de formulação de definições e aponta uma circularidade viciosa quando se tenta aplicá-lo ao ser. Toda definição contém a expressão "é", ainda que implicitamente, e portanto

Aristóteles. Metafísica. Tradução Marcelo Perine. Volume II. $2^{a}$ ed. São Paulo, Edições Loyola, 2005, p. 105 (998b 21-24).

${ }^{6}$ Segue leitura semelhante Studtmann, P.. "Aristotle's Categories". In: The Stanford Encyclopedia of Philosophy (Winter 2013 Edition), Edward N. Zalta (ed.), HTML version, 2.1. URL = <http://plato.stanford.edu/archives/win2013/entries/aristotle-categories/>.

${ }^{7}$ Kant, I.. Crítica da Razão Pura. (Os Pensadores) Tradução Valério Rohden e Udo Baldur Moosburger. São Paulo, Abril Cultural, 1980, p. 300 e seguintes (B 626 e seguintes).

${ }^{8}$ Heidegger, M.. Os Problemas Fundamentais da Fenomenologia. Tradução Marco Antônio Casanova. $2^{\mathrm{a}}$ ed.. Petrópolis: Vozes, 2012, p. 86 (GA 24, p. 77).

\begin{tabular}{|c|c|l|l|l|l|}
\hline intuitio & $\begin{array}{c}\text { ISSN } \\
1983-4012\end{array}$ & Porto Alegre & Vol.7- $\mathrm{N}^{\circ} .1$ & $\begin{array}{c}\text { Junho } \\
2014\end{array}$ & p.32-42 \\
\hline
\end{tabular}


parece presumir ser. Uma definição de ser não conseguiria eliminar da definição o próprio termo que está por se definir.

Isto implica que "ser" não entra sem problemas na posição de sujeito de uma enunciação categórica. Com isso Heidegger recusa à noção de ser qualquer inserção na ordem de gêneros e espécies, e pode já concluir o aspecto mais específico da diferença ontológica: ser não é um ente, no caso, um ente subsistente a ser determinado mediante asserções predicativas.

Uma anotação posterior de Heidegger alerta, no entanto, que "nada pode ser decidido sobre o Seer [Seyn] com auxílio desta conceituação". Dreyfus sugere aqui um alerta para se resistir à tentação de tomar o ser como um evento ou um processo ${ }^{9}$, uma vez que já não se pode tomá-lo com umas substância ou um objeto ordinário. Aqui insinua-se um quietismo que deveria prevenir qualquer tipo de pretensão assertórica a respeito do ser, mesmo que não especificamente predicativa, e em relação ao qual é duvidoso que o próprio Heidegger conseguiu manter-se assíduo. É difícil justificá-lo neste momento, mas é fácil ver que ele é coerente com a inversão posterior da prioridade tradicionalmente atribuída à modalidade da atualidade em relação à da possibilidade em relação ao modo de ser do seraí (SZ, 143). Qualquer tipo de efetividade, seja de um evento ou de um processo, ainda diz pouco para o ente que questiona por suas possibilidades mais próprias no modo irredutível à qualquer estado de coisas que a angústia e a temporalidade própria sugerem. É natural esperar daqui implicações para a questão mais ulterior do sentido de ser, dado o imbricamento originário entre ser-aí e ser.

Ser não comporta apresentação ordinária (SZ, 4). A obtenção deste corolário é mais sutil, embora ele esteja implicado nos anteriores. Aqui segue-se de perto o preconceito da tradição, que diz que "ser" é um conceito que pode ser entendido por si mesmo [selbstverständliche], quer dizer, óbvio e natural, evidente em si mesmo, autoexplicativo. Heidegger então amplia seu horizonte de consideração para além da intencionalidade proposicional até então considerada, do conhecimento e do enunciado categórico, e lembra que o ser é presumido e compreendido com satisfatória competência mesmo nos comportamentos não explicitamente temáticos, especificamente, em cada comportamento dirigido ao ente, ainda no sentido estrito de coisa subsistente, e em cada comportamento de si a si mesmo. Isto no entanto mostra apenas que nos orientamos constante e cotidianamente numa compreensão vaga e mediana de ser que não sabemos com clareza explicitar nem justificar e que não foi ainda apreciada em todas as suas implicações e fundamentos.

Quando dizemos que "ser" é uma noção autoexplicativa e evidente por si mesma, o que queremos dizer é que aquilo que esta expressão significa não precisa ser exibido ou provado diretamente, uma vez que já é algo de presumido em qualquer exibição ou prova. Esta presunção, no entanto, importa na verdade numa impossibilidade de proceder-se à uma tal demonstração, o que por seu lado não surpreende à luz das duas dificuldades mencionadas anteriormente. Se o ser pudesse ser

${ }^{9}$ Dreyfus, H. L.. Being-in-the-World: A Commentary on Heidegger's Being and Time. Fourth Printing. Cambridge; London: The MIT Press, 1993, p. 11.

\begin{tabular}{|c|c|l|l|l|l|}
\hline intuitio & $\begin{array}{c}\text { ISSN } \\
1983-4012\end{array}$ & Porto Alegre & Vol.7- $\mathrm{N}^{\circ} .1$ & $\begin{array}{c}\text { Junho } \\
2014\end{array}$ & p.32-42 \\
\hline
\end{tabular}


mostrado em si mesmo, seria um ente subsistente e enunciados a seu respeito poderiam ser verificados, definições sugeridas, um gênero poderia então ser demarcado etc. Ao mencionar Kant e apontar um enigma que reside a priori na intencionalidade, Heidegger dá à questão do ser a dificuldade metodológica dos juízos sintéticos a priori, presunções ontológicas que escapam tanto à tautologia lógica quanto à verdade contingente verificável.

Os três resultados obtidos, considerados com honestidade, deixam a investigação a que Heidegger se propõe entregue a uma inusitada perplexidade. Ao que parece, ela deve abandonar a expectativa de avançar em asserções e resultados concretos e vê-se reduzida a mera formulação verbal da questão acerca do ser. A obstrução em relação a qualquer abordagem assertórica parece esvaziar mesmo a mera expectativa de se sustentar de modo consequente esta questão, uma vez que, ordinariamente, perguntas são orientadas para a obtenção de asserções que sirvam de resposta. Além disso, perguntas seguem a forma lógica destas asserções que lhes respondem, e cuja aplicabilidade ao ser restou de todo problemática. Heidegger tem bons motivos para duvidar que esteja mesmo colocando uma pergunta que faça de algum modo sentido. O passo que resta natural portanto é voltarse a esta questão, articular em detalhes cada um dos seus elementos e explicitar do que ela se trata (ST, 5). O desenvolvimento posterior é a conhecida opção metodológica da analítica existencial, voltar-se para o próprio ente que formula e sustenta a questão de ser, mas toma-lo como aptidão concreta para a própria questão, modalizando a abordagem numa possibilidade concreta em aberto para os interlocutores, e contornando deste modo o efeito objetificante do discurso assertórico. É o que dá um contexto concreto de aplicação à doutrina metodológica dos indícios formais: os enunciados de Ser e Tempo reivindicam um modo de leitura extraordinário, não como asserções de fatos antropológicos, mas como remissões ao poder ser que a cada vez é aberto aos interlocutores como relevante e significativo numa medida maior ou menor.

Antes porém que possa propor esta opção de modo consequente, Heidegger deveria ter amarrado uma ponta solta que se insinuou ainda na discussão do primeiro preconceito da tradição. É o que vemos a seguir.

\section{A bifurcação da ontologia fundamental}

Há um ponto do qual Heidegger chega a se aproximar mas não o enfrenta no contexto desta discussão como deveria, e que oferece obstáculos não desprezíveis às pretensões metodológicas extraordinárias da ontologia fundamental sustentada em Ser e Tempo. Quando examina o primeiro preconceito da tradição, que se contenta em dizer que ser é conceito mais universal, Heidegger já teria o que precisava na aporia que resultava ao se considerar o ser como um gênero de qualquer sorte. No entanto, acha ainda por bem comentar a dificuldade que Aristóteles teria mostrado para se trazer todos

\begin{tabular}{|c|c|c|c|c|c|}
\hline intuitio & $\begin{array}{c}\text { ISSN } \\
1983-4012\end{array}$ & Porto Alegre & Vol.7 - $\mathrm{N}^{\mathrm{o}} .1$ & $\begin{array}{l}\text { Junho } \\
2014\end{array}$ & p. $32-42$ \\
\hline
\end{tabular}


os sentidos em que se usa a expressão "ser" a uma noção ou nota real comum ${ }^{10}$. Ao fazer isso, no entanto, tocou num problema mais complicado do que estava em questão e ao referir-se à solução aristotélica com a expressão medieval um tanto vaga "unidade da analogia", e insinuar que tal solução não chegara a uma "clareza de princípio" a respeito destes "nexos categoriais", parece estar contornando o incômodo fato de que Aristóteles e seus seguidores julgavam ter chegado a uma resposta consequente para este problema e portanto para a própria questão do sentido de ser.

"Ser" se diz de diversas maneiras que não são facilmente trazidas a um só sentido: acidente, substância, verdadeiro e falso, em potência ou em ato. A solução de Aristóteles é que há um sentido prioritário que articula os demais ${ }^{11}$ (Metafísica, 1028a 8 - 1028b 8). "Ser" teria um significado focal, bem explicado por Jonathan Barnes: "Uma palavra tem um significado focal se ela é usada de diferentes modos, um dos quais é primário e os outros são derivados, de modo que a explicação do modo derivado de uso contém a explicação do modo primário"12. O sentido primordial proposto é ousia, substância, e logo, todos os outros sentidos são explicados a partir deste, como esboça Aristóteles:

\begin{abstract}
Assim também o ser se diz em muitos sentidos, mas todos em referência a um único princípio: algumas coisas são ditas ser porque são substância, outras porque afecções da substância, outras porque são vias que levam à substância, ou porque são corrupções, ou privações, ou qualidades, ou causas produtoras ou geradoras tanto da substância como do que se refere à substância, ou porque negações de algumas destas ou, mesmo, da própria substância $[\ldots]^{13}$
\end{abstract}

E a partir deste sentido é possível então se propor uma ciência do $\operatorname{ser}^{14}$ (Metafísica, 1003b 1119). Aqui abre-se uma outra frente de debate especialmente delicada para Heidegger, por que compatível com a continência da diferença ontológica mas frontalmente divergente dos resultados ulteriores da analítica existencial e da própria opção metodológica em se fundar uma ontologia fundamental numa analítica do ser-aí: ser não é um ente, e portanto, não é um ente subsistente, mas é, de um modo principal ou acessório, o ser de um ente subsistente.

Esta alternativa abre ainda diversas possibilidades. Uma delas, razoavelmente econômica em pressuposições, é a seguinte. Todos os sentidos de ser apontados de algum modo dizem respeito a diferentes aspectos da aptidão discursiva apofântica. Acidentes parecem ser aquilo que retemos em predicações, ser verdadeiro ou falso é a bivalência necessária de qualquer sentença, potência e ato antecipa a modalização de enunciados em possíveis ou efetivos. Por fim, substância parece reter

\footnotetext{
${ }^{10}$ Aristóteles. Metafísica. Tradução Marcelo Perine. Volume II. $2^{\mathrm{a}}$ ed. São Paulo, Edições Loyola, 2005, p. 213 214 (Metafísica, 1017a 6 - 1017b 10).

${ }^{11}$ Aristóteles. Metafísica. Tradução Marcelo Perine. Volume II. $2^{\mathrm{a}}$ ed. São Paulo, Edições Loyola, 2005, p. 288289 (1028a $8-1028 b$ 8).

${ }^{12}$ Barnes, J.. "Metaphysics". In: Barnes, J., The Cambridge Companion to Aristotle. New York: Cambridge University Press, 1995, p. 76.

${ }^{13}$ Aristóteles. Metafísica. Tradução Marcelo Perine. Volume II. $2^{a}$ ed. São Paulo, Edições Loyola, 2005, p. 133 (1003b 5-10).

${ }^{14}$ Aristóteles. Metafísica. Tradução Marcelo Perine. Volume II. $2^{\mathrm{a}}$ ed. São Paulo, Edições Loyola, 2005, p. 133 (1003b, 11-19).
}

\begin{tabular}{|c|c|c|c|c|c|}
\hline intuitio & $\begin{array}{c}\text { ISSN } \\
1983-4012\end{array}$ & Porto Alegre & Vol.7 $-\mathrm{N}^{\mathrm{o}} .1$ & $\begin{array}{l}\text { Junho } \\
2014\end{array}$ & p. $32-42$ \\
\hline
\end{tabular}


aquilo de que se tratam as sentenças predicativas, aquilo a que o discurso apofântico se remete. Se o sentido primordial de ser é a substância, e a substância é aquilo de que se trata o discurso apofântico, elucidar o sentido de ser é nada mais do que elucidar o sentido das proposições apofânticas.

É claro que em resultados avançados da analítica existencial, Heidegger vai enfrentar esta posição, ao sustentar que é uma tendência cotidiana e impessoal tomar todo ente como um ente subsistente, mas que afinações afetivas especificamente graves, como a angústia ou o tédio, e os comportamentos compreensivos possibilitados por estas afinações, como o ser para a morte e o ser devedor, nos sugerem que isso é precipitado em relação ao ente que nós mesmos somos. Mas seria importante estabelecer por que ela não se apresenta como a primeira opção metodológica, como pareceu a toda a tradição metafísica que lhe antecedeu. Heidegger terá melhores condições de sustentar isto quando considerar que o próprio questionamento do ser é ele próprio um modo de ser que não é facilmente trazido a este modo de abordagem (SZ, 12), mas pode preliminarmente pôr em suspenso a presunção de que o sentido primordial de ser é o de substância, pelo menos na medida em que esta presunção não é livre de outras que merecem alguma elucidação em pormenor, e isto é provavelmente o que ele quer dizer quando alega que persiste alguma obscuridade nestes "nexos categoriais".

Heidegger não precisa recusar frontalmente a abordagem da questão do sentido de ser como uma elucidação do sentido das proposições apofânticas. Em verdade, ao propor que a compreensão de ser segue uma estrutura articulada na expressão "algo como algo" (SZ, 149), ao apontar uma tendência cotidiana e imediata a se tomar todo ente realidade e substância (SZ, 201), ao propor desvelamento como condição de sentido da correspondência veritativa (SZ, 220), ao inverter a prioridade tradicional entre atualidade e possibilidade (SZ, 143-144), Heidegger parece estar seguindo de perto vários aspectos de um mesmo fio condutor dado pela forma lógica dos enunciados apofânticos. Apenas recusaria que esta elucidação se esgotasse numa mera consideração de funções linguísticas ou lógicas, e tomaria esta própria competência discursiva como um comportamento cuja significância e relevância para quem a desempenha requereria uma abordagem de outra ordem e mais fundamental. Desde modo, elucidar propriamente as condições de sentido da proposição categórica nunca seria elucidar tão somente a proposição categórica:

Nós nos detivemos na proposição enunciativa porque esta forma proposicional pertence à essência do discurso cotidiano e porque só chegamos efetivamente a compreender o que há de característico e sedutor nesta forma proposicional se conseguimos avançar através dela até o cerne de algo totalmente diverso, a partir do qual pela primeira vez a essência da proposição se mostra, neste sentido, como compreensível. Com isto, está dito: trata-se de mostrar, segundo sua própria possibilidade interna, onde se encontra a estrutura mesma da proposição. Trata-se de tornar visíveis aquelas ligações, no interior das quais a proposição enquanto tal já se movimenta e repousa - ligações que não são criadas pela primeira vez pela proposição, mas das quais a proposição carece para a sua própria essência. Com este ponto de partida, a proposição e o logos já alcançam uma dimensão totalmente diversa. Ela não é mais agora o centro da problemática, mas o que se dissolve em

\begin{tabular}{|c|c|c|c|c|c|}
\hline intuitio & $\begin{array}{c}\text { ISSN } \\
1983-4012\end{array}$ & Porto Alegre & Vol.7 - $\mathrm{N}^{\circ} .1$ & $\begin{array}{l}\text { Junho } \\
2014\end{array}$ & p. $32-42$ \\
\hline
\end{tabular}


uma dimensão mais amplamente extensa. ${ }^{15}$

Esta estrutura totalmente diversa, que transcende a estrutura proposicional e lhe dá condições de possibilidade, sabemos antecipadamente, é a temporalidade [Zeitlichkeit]. De fato, Heidegger pretende mostrar que o ente subsistente [Vorhanden] a que correspondem enunciados proposicionais tem sua possibilidade de ser num aspecto específico da temporalidade. Mesmo não problematizando diretamente a prioridade da ousia sobre os outros sentidos de ser ligados à função proposicional, Heidegger reivindica um sentido originário deste termo como o que está disponível na experiência cotidiana, a saber, coisas ordinárias e bens patrimoniais:

\begin{abstract}
Aquilo que se acha assim diante das mãos [vor-handen] é considerado pela experiência cotidiana como o ente em primeira linha. Os haveres e os bens disponíveis, os bens, se mostram como o ente pura e simplesmente, em grego ousia. Ainda na época de Aristóteles, em um momento em que ousia já tinha adquirido um significado terminológico-filosófico fixo, essa expressão tinha ao mesmo tempo o significado de haveres, estado de posse, fortuna. O autêntico significado préfilosófico de ousia ainda se manteve. De acordo com isso, ente significa o mesmo que o ente subsistente disponível. ${ }^{16}$
\end{abstract}

Heidegger acha que traduz melhor todas as implicações de ousia com o termo Anwesen, que significa uma propriedade imóvel, como um terreno ou uma casa, e que mantém radical comum com Anwesenheit, que denota a presença física de alguém ou de algo, e com Wesen, essência:

Todas estas determinações do ser se fundam e se mantém reunidas no que, sem questionarem o sentido do ser, os gregos experimentavam e chamavam de ousia, ou de maneira mais completa, parousia. A falta habitual de reflexão traduz parousia por "substância" e assim não lhe atinge o sentido. Em alemão temos uma expressão adequada para dizer parousia na palavra An-wesen, que significa um bem territorial e rural privado. Ainda ao tempo de Aristóteles ousia se emprega simultaneamente nesse sentido $e$ no sentido filosófico da palavra. Algo vem à essência e se faz presente [Etwas west an]. Sustenta-se em si e assim se coloca [Es steht in sich und stellt sich so da]. É. Para os gregos, "ser" no fundo significa presença física $[$ Anwesenheit $] .{ }^{17}$

Acontece que o comportamento intencional que toma algo como ente subsistente no sentido de diante e disponível para a vista e para as mãos, e como presente no sentido de fisicamente disposto em si mesmo, é um comportamento que é temporalmente orientado, segundo alega Heidegger. Os sentidos de algo observável pensado em Vorhanden e de presença física pensado em Anwesen e Anwesenheit adquirem um sentido temporal de "presente", enquanto algo coordenado ao futuro e ao passado, na expressão Gegenwart, e que partida literalmente em seus componentes, pode ser lida como o que repousa ou espera diante ou contraposto:

${ }_{15}$ Heidegger, M.. Os Conceitos Fundamentais da Metafísica: Mundo, Finitude, Solidão. Tradução Marco Antônio Casanova. Rio de Janeiro: Forense Universitária, 1983, p. 348 (GA 29-30, p. 440).

${ }^{16}$ Heidegger, M.. Os Problemas Fundamentais da Fenomenologia. Tradução Marco Antônio Casanova. $2^{\text {a }}$ ed.. Petrópolis: Vozes, 2012, p. 161 (GA 24, p. 153). A tradução foi modificada para atender ao que ora se argumenta.

${ }^{17}$ Heidegger, M.. Introdução à Metafísica. Tradução Emmanuel Carneiro Leão. Rio de Janeiro: Tempo Brasileiro, 1966, p. 111 (GA 40, p. 65). A tradução foi modificada para atender ao que ora se argumenta.

\begin{tabular}{|c|c|c|c|c|c|}
\hline intuitio & $\begin{array}{c}\text { ISSN } \\
1983-4012\end{array}$ & Porto Alegre & Vol. $7-\mathrm{N}^{\circ} .1$ & $\begin{array}{l}\text { Junho } \\
2014\end{array}$ & p. $32-42$ \\
\hline
\end{tabular}


O legein ele mesmo, ou o noein, a mera percepção de algo subsistente e diante da vista em sua pura subsistência e disponibilidade, que já Parmênides havia tomado como guia para a interpretação do ser, tem a estrutura temporal do puro "presentificar" [Gegenwärtigens] de algo. Portanto, o ente que se mostra neste presentificar e para este presentificar, e que é compreendido como o que é propriamente ente, recebe sua interpretação em alusão ao contra-posto [Gegenwart], ou seja, é concebido como presença física [Anwesenheit] (ousia) (SZ, 25-26).

O que Heidegger alega em alemão não se perde na tradução, visto que o nosso termo "presente" captura os três sentidos ${ }^{18}$. Tão pouco depende das sinonímias mencionadas. Na asserção de enunciados os presumimos consequentes em termos de verdade e, com isso, queremos dizer, que são verificáveis ao menos em princípio. Na verificabilidade do enunciado presumimos que aquilo de que tratam está disponível e disposto em si mesmo para o comportamento de verificação, dizemos então que quem duvida do que é afirmado pode verificar por si mesmo "agora", o que importa em algum tipo de simultaneidade temporal entre intencionalidade e realidade. Isso fica ainda mais claro quando consideramos asserções futuras e passadas e perguntamos por suas condições de verificabilidade. Vê-se então que de um modo ou de outro tais asserções presumem se remeter a um presente de segunda ordem, projetado idealmente no passado ou no futuro. Presume-se então que se alguém estivesse presente no passado, ou se estiver presente no futuro, poderia ou poderá verificar o que ora se profere (e é por isso que mesmo asserções que não são de fato verificáveis para uma comunidade concreta de falantes ainda tem sentido para esta comunidade).

Se Heidegger estiver certo a respeito das implicações temporais que o termo "ousia" tem em Aristóteles, então o que um interlocutor aristotélico entende por "substância" tem presunções temporais que merecem um esclarecimento prévio, o que por seu lado pede uma elucidação do próprio tempo, já que qualquer sentido temporal de "presente" se remete a uma estrutura mais abrangente dentro da qual algo é pensado como tal. Dado isso, a expectativa de que o ser é sempre o ser de um ente subsistente, e logo, de que todo modo de ser pode ser determinado por proposições assertóricas, enfrentaria então uma circularidade viciosa quando sustentada em relação ao próprio tempo, como Heidegger sugere um pouco adiante: "O tempo é tomado ele mesmo como um ente entre outros entes, e tenta-se então apreendê-lo em sua estrutura de ser no horizonte de uma compreensão de ser ingênua e implicitamente orientada nele mesmo" (SZ, 26). Todos os sentidos de ser que dizem respeito a algum aspecto formal da proposição remetem ao sentido de ousia. Este, por seu lado, tem um sentido temporal que requer esclarecimento, o que demanda o esclarecimento do próprio tempo, esclarecimento este que não pode então contar sem problemas com proposições assertóricas, cuja sentido é justamente o que está em questão. A conclusão preliminar é que um outro sentido de ser que não aquele articulado no enunciado categorial, quer dizer, um outro modo de ser diverso do ente subsistente precisa ser trazido à consideração.

${ }^{18} \mathrm{O}$ sentido patrimonial também está retido no uso da expressão para designar uma doação ou prenda de alguém para outrem, o que confirma a simetria apontada por Heidegger entre presença física e disponibilidade material dos objetos na cotidianidade.

\begin{tabular}{|c|c|l|l|l|l|}
\hline intuitio & $\begin{array}{c}\text { ISSN } \\
1983-4012\end{array}$ & Porto Alegre & Vol.7- $\mathrm{N}^{\mathrm{o}} .1$ & $\begin{array}{c}\text { Junho } \\
2014\end{array}$ & p.32-42 \\
\hline
\end{tabular}


Heidegger vai evitar a tentação de propor que o tempo seja ele próprio um ente em qualquer sentido, sugerindo, numa formulação célebre e enigmática, que a temporalidade "se temporaliza" (SZ, 328). Não é o lugar para começar a se esclarecer o que isso possa querer dizer, mas sabemos que Heidegger pretende mostrar que a temporalidade "é" o horizonte de sentido de um ente de caráter ontológico peculiar (SZ, 17), cujo modo de ser sustenta as condições de possibilidade do ente subsistente enquanto tal em diversos comportamentos, inclusive, a asserção e verificação de enunciados, o que viabiliza por seu lado a simultaneidade mencionada acima entre presentificar, compreender o ser do ente subsistente (intencionalidade proposicional) e presença (realidade). $\mathrm{O}$ modo de ser deste ente peculiar é um sentido de "ser" que não foi exaurido na abordagem proposicional, justamente o sentido que está em questão no "sou" proferido em primeira pessoa como ser empenhado em possibilidades abertas num mundo concreto, quer dizer, ser para possibilidades que lhe importam em alguma medida e que se abrem na defrontação com o ente intramundano. Este seria o Cogito como Heidegger consideraria bem interpretado (SZ, 211), e que não seria primordialmente predicativo nem assertórico.

\section{Referências}

Aristóteles. Metafísica. Tradução Marcelo Perine. Volume II. $2^{a}$ ed. São Paulo, Edições Loyola, 2005.

Barnes, J. "Metaphysics". In: Barnes, J., The Cambridge Companion to Aristotle. New York: Cambridge University Press, 1995.

Dreyfus, H. L. Being-in-the-World: A Commentary on Heidegger's Being and Time. Fourth Printing. Cambridge; London: The MIT Press, 1993.

Gadamer, H.-G. Hermenêutica em Retrospectiva - Volume I. 2 ${ }^{\mathrm{a}}$ ed. Tradução Marco Antônio Casanova. Petrópolis: Vozes, 2007.

Heidegger, M. Introdução à Metafísica (GA 40). Tradução Emmanuel Carneiro Leão. Rio de Janeiro: Tempo Brasileiro, 1966.

Heidegger, M. Os Conceitos Fundamentais da Metafísica: Mundo, Finitude, Solidão (GA 29-30). Tradução Marco Antônio Casanova. Rio de Janeiro: Forense Universitária, 2006.

Heidegger, M. Os Problemas Fundamentais da Fenomenologia (GA 24). $2^{\text {a }}$ ed.. Tradução Marco Antônio Casanova. Petrópolis: Vozes, 2012.

Heidegger, M. Sein und Zeit. Neunzehnte Auflage. Tübingen: Max Niemeyer Verlag, 2006.

Kant, I. Crítica da Razão Pura (Os Pensadores). Tradução Valério Rohden e Udo Baldur Moosburger. São Paulo: Abril Cultural, 1980.

Studtmann, P. "Aristotle's Categories", In: The Stanford Encyclopedia of Philosophy (Winter 2013 Edition), Edward N. Zalta (ed.), http://plato.stanford.edu/archives/win2013/entries/aristotle-categories/

\begin{tabular}{|c|c|c|c|c|c|}
\hline intuitio & $\begin{array}{c}\text { ISSN } \\
1983-4012\end{array}$ & Porto Alegre & Vol.7 - $\mathrm{N}^{\mathrm{o}} .1$ & $\begin{array}{l}\text { Junho } \\
2014\end{array}$ & p. $32-42$ \\
\hline
\end{tabular}

